\title{
PERAN PETUGAS KESEHATAN DAN PENGETAHUAN KELUARGA TERHADAP PENINGKATAN KEMAMPUAN MERAWAT KLIEN GANGGUAN JIWA DI RUMAH
}

\author{
Edi Purnomor ${ }^{1}$, Zulhaini Sartika A. Pulungan ${ }^{1}$, Andi Milawati \\ ${ }^{1}$ Jurusan Keperawatan Poltekkes Kemenkes Mamuju \\ ${ }^{2}$ Jurusan Keperawatan STIKES Andini Persada Mamuju
}

\begin{abstract}
Mental disorder schizophrenia is a disorder psychic who ranks second in diseases that cause the greatest burden after heart disease. Its burden of mental disorders is mainly felt by the families who have family members with mental disorders. Patients with mental disorders who live with the family does not always indicate the best condition for the recovery of the client. The purpose of this study was to determine the effect of the role of the clerk and the knowledge of the family in improving the ability of families caring for clients with mental disorders at home. This research method is descriptive quantitative research design descriptive analytic approach cross sectional study. The samples used were 30 families who have family members experiencing mental disorders withpurposivesampling method. The research was conducted in Puskesmas Ulumanda Majene district. Results showed no effect between family knowledge $(\mathrm{p}=0.005)$ and the role of health care workers $(\mathrm{p}=0.008)$ with the ability of families in caring for clients with mental disorders at home. Conclusion the role of health workers and knowledge affect the ability of families caring for clients with mental disorders at home. Advised the family to be more active in seeking information about the treatment of people with mental disorders at home and health officials often approach to the family to help care clients with mental disorders.
\end{abstract}

Keyword: officer role, knowledge of the family, mental disorders.

\section{PENDAHULUAN}

Gangguan jiwa (mental disorder) salah satu dari empat masalah kesehatan utama di negara-negara maju, modern dan industri. Keempat masalah kesehatan utama tersebut adalah penyakit degeneratif, kanker, gangguan jiwa dan kecelakaan. Gangguan jiwa tidak dianggap sebagai gangguan yang menyebabkan kematian secara langsung, namun beratnya gangguan tersebut dalam arti ketidakmampuan secara individu maupun kelompok akan menghambat pembangunan karena mereka tidak produktif dan tidak efisien (Hawari, 2007). Gangguan jiwa adalah gejala atau pola tingkahlaku psikologi yang tampak secara klinis pada seseorang, yang berhubungan dengan keadaan distres dan ketidakmampuan. Gangguan jiwa dapat meningkatkan risiko terhadap kematian, nyeri, ketidakmampuan atau kehilangan kebebasan, dan tidak jarang respon tersebut dapat diterima pada kondisi tertentu (Maramis, 2005).

Gangguan jiwa di Indonesia menjadi masalah yang cukup serius. Berdasarkan data Depkes (2001) satu dari lima penduduk Indonesia menderita gangguan jiwa. Data dari
WHO pada tahun 2006, terdapat 26 juta penduduk Indonesia mengalami gangguan jiwa. Berdasarkan data tersebut dapat disimpulkan bahwa angka gangguan jiwa di Indonesia mencapai $12-16 \%$ dari populasi penduduk. Hasil SKMRT menunjukan gangguan mental emosional pada usia diatas lima belas tahun sebanyak 140 orang per 1.000 penduduk dan usia lima sampai empat belas tahun sebanyak 104 orang per 1.000 penduduk (Maramis, 2005).

World Health Organization (WHO) menyebutkan masalah utama gangguan jiwa di dunia adalah skizofrenia, depresi unipolar, penggunaan alkohol, gangguan bipolar, gangguan obsesis kompulsif (Stuart \& Laraia, 2005). Skizofrenia adalah sekumpulan sindroma klinik yang ditandai dengan perubahan kognitif, emosi, persepsi dan aspek lain dari perilaku (Kaplan, Saddock, \& Grebb, 2010). Gejala negatif dari skizofrenia meliputi sulit memulai pembicaraan, afek tumpul atau datar, berkurangnyamotivasi, berkurangnya atensi, pasif, apatis dan penarikan diri secara sosial dan rasa tidak nyaman (Videbeck, 2008). 
Menurut (Hawari, 2007) salah satu kendala dalam upaya penyembuhan pasien gangguan jiwa adalah pengetahuan masyarakat dan keluarga. Keluarga dan masyarakat menganggap gangguan jiwa penyakit yang memalukan dan membawa aib bagi keluarga. Penilaian masyarakat terhadap gangguan jiwa sebagai akibat dari dilanggarnya larangan, guna-guna, santet, kutukan dan sejenisnya berdasarkan kepercayaan supranatural. Dampak dari kepercayaan mayarakat dan keluarga, upaya pengobatan pasien gangguan jiwa dibawa berobat ke dukun atau paranormal. Kondisi ini diperberat dengan sikap keluarga yang cenderung memperlakukan pasien dengan disembunyikan, diisolasi, dikucilkan bahkan sampai ada yang dipasung. Keluarga merupakan faktor yang sangat penting dalam proses kesembuhan klien yang mengalami gangguan jiwa. Kondisi keluarga yang terapeutik dan mendukung klien sangat membantu kesembuhan klien dan memperpanjang kekambuhan.

Keluarga sebagai "perawat utama" dari klien memerlukan treatment untuk meningkatkan pengetahuan dan keterampilan dalam merawat klien. Berdasarkan evidance basedpractice psikoedukasi keluarga adalah terapi yang digunakan untuk memberikan informasipada keluarga untuk meningkatkan keterampilan mereka dalammerawat anggota keluarga mereka yang mengalami gangguan jiwa, sehingga diharapkan keluarga akan mempunyai koping yang positif terhadap stresdan beban yang dialaminya (Goldenberg \& Goldenberg, 2004).

Sulawesi Barat adalah provinsi ke-33 di Indonesia yang merupakan pemekaran dari provinsi induk Sulawesi Selatan. Provinsi Sulawesi Barat belum mempunyai rumah sakit jiwa sehingga penanganan pasien gangguan jiwa belum optimal. Berdasarkan studi pendahuluan di Kabupaten Majene, terdapat 217 orang mengalami gangguan jiwa. Peningkatan penderita gangguan jiwa tersebut sudah selayaknya menjadi perhatian masyarakat sebab penyelesaian masalah gangguan jiwa bukan hanya tanggung jawab tenaga kesehatan namun juga perlu keterlibatan aktif semua pihak dalam hal ini keluarga dan masyarakat. Berdasarkan dari data-data tersebut, peneliti tertarik untuk mengetahui faktor-faktor apa saja yang mempengaruhi kemampuan keluarga dalam merawat klien gangguan jiwa di rumah.

\section{METODE \\ Jenis Penelitian}

Metode yang digunakan dalam penelitian ini adalah analitik dengan rancangan cross sectional.

\section{Populasi dan Sampel}

Populasi dalam penelitian ini adalah semua keluarga di wilayah kerja Puskesmas Ulumanda Kabupaten Majene. Sampel yang digunakan adalah 30 keluarga yang memiliki anggota keluarga mengalami gangguan jiwa dengan metode pengambilan sampel purposive sampling.

\section{Teknik Pengumpulan Data}

Instrument yang digunakan dalam penelitian ini adalah kuesioner yang terdiri dari karakteristik responden dan variabel yang akan diteliti (tingkat pendidikan keluarga, kemampuan keluarga, pengetahuan keluarga dan peran petugas kesehatan).

\section{Analisa data}

Analisis data dilakukan dengan analisis deskriptif dengan menampilkan distribusi dan persentase dari tiap variabel. Selanjutnya dilakukan analisis untuk menguji hipotesis menggunakan fisher's exact test untuk mengetahui pengaruh pengetahuan keluarga dan peran petugas kesehatan terhadap kemampuan keluarga dalam merawat klien gangguan jiwa, dengan tingkat kepercayaan $95 \%(\alpha 0,05)$.

\section{HASIL PENELITIAN}

Karakteristik Responden

Melihat tabel 1. berdasarkan umur sebagian besar responden berada dalam rentang umur 30 - 40 tahun yaitu 14 responden (46.7\%). Jenis kelamin laki-laki sebanyak 16 responden (53.3\%). Beragama Islam dan menganut suku mandar 30 responden (100\%). Pekerjaan responden sebagai tani terbanyak 18 responden $(60 \%)$. Status pernikahan telah menikah sebanyak 24 responden (80\%). Hubungan responden dengan klien sebagai anak 9 responden (30\%) dan sebagai saudara kandung yaitu 9 responden $(30 \%)$. Klien gangguan jiwa sebagian besar berjenis kelamin laki-laki sebanyak 21 orang (70\%). Kondisi klien belum pernah dirawat di rumah sakit jiwa sebanyak 27 orang $(90 \%)$.

Tabel 2. menunjukkan bahwa responden yang terbanyak adalah tidak mampu 
merawat klien gangguan jiwa dirumah 21 responden (70\%). Responden yang memiliki pengetahuankurang tentang gangguan jiwa 24 responden $(80 \%)$. Responden yang memiliki tingkat pendidikan tinggi 1 responden $(3.3 \%)$ dan yang memiliki tingkat pendidikan rendah yaitu 29 responden (96.7\%). Peran petugas kesehatan yang kurang berperan 21 responden (70\%).

Tabel 1. Distribusi Frekuensi Karakteristik Responden dan Klien ( $=30)$

\begin{tabular}{|c|c|c|}
\hline Karakteristik Responden dan Klien & $\mathrm{n}=\mathbf{3 0}$ & Persen (\%) \\
\hline $\begin{array}{l}\text { Umur reponden (tahun) } \\
\begin{array}{l}30-40 \\
41-50 \\
51-60 \\
61-70 \\
>70\end{array}\end{array}$ & $\begin{array}{l}14 \\
5 \\
7 \\
3 \\
1\end{array}$ & $\begin{array}{l}46.7 \\
16.7 \\
23.3 \\
10.0 \\
3.3\end{array}$ \\
\hline $\begin{array}{l}\text { Jenis Kelamin Responden } \\
\text { Laki-laki } \\
\text { Perempuan }\end{array}$ & $\begin{array}{l}16 \\
14\end{array}$ & $\begin{array}{l}53.3 \\
46.7\end{array}$ \\
\hline $\begin{array}{l}\text { Agama Responden } \\
\text { Islam }\end{array}$ & 30 & 100 \\
\hline $\begin{array}{c}\text { Suku Responden } \\
\text { Mandar }\end{array}$ & 30 & 100 \\
\hline $\begin{array}{l}\text { Pekerjaan Responden } \\
\text { Tani } \\
\text { IRT } \\
\text { PNS } \\
\text { Wiraswasta }\end{array}$ & $\begin{array}{c}18 \\
9 \\
1 \\
2\end{array}$ & $\begin{array}{l}60 \\
30 \\
3.3 \\
6.7\end{array}$ \\
\hline $\begin{array}{l}\text { Status Penikahan Responden } \\
\text { Menikah } \\
\text { Belum Menikah } \\
\text { Duda } \\
\text { Janda } \\
\end{array}$ & $\begin{array}{c}24 \\
1 \\
2 \\
3\end{array}$ & $\begin{array}{c}80 \\
3.3 \\
6.7 \\
10 \\
\end{array}$ \\
\hline $\begin{array}{l}\text { Hubungan Responden dengan Klien } \\
\text { Orang Tua } \\
\text { Anak } \\
\text { Saudara } \\
\text { Suami } \\
\text { Istri }\end{array}$ & $\begin{array}{l}3 \\
9 \\
9 \\
2 \\
7\end{array}$ & $\begin{array}{c}10 \\
30 \\
30 \\
6.7 \\
23.3\end{array}$ \\
\hline $\begin{array}{l}\text { Jenis Kelamin Klien } \\
\text { Laki-Laki } \\
\text { Perempuan }\end{array}$ & $\begin{array}{c}21 \\
9\end{array}$ & $\begin{array}{l}70 \\
30\end{array}$ \\
\hline $\begin{array}{l}\text { Kondisi Klien } \\
\text { Belum Pernah dirawat di RSJ } \\
\text { Pernah dirawat di RSJ }\end{array}$ & $\begin{array}{c}27 \\
3\end{array}$ & $\begin{array}{l}10 \\
90\end{array}$ \\
\hline
\end{tabular}

Menggunakan uji statistik Pearson Fisher's Exact Test diperoleh hasil, bahwa ada pengaruh pengetahuan keluarga $(p=0,005)$ dan peran petugas kesehatan $(p=0,008)$ dengan kemampuan keluarga dalam merawat klien gangguan jiwa dirumah, dengan nilai $p<0,05$.

\section{PEMBAHASAN}

Hasil penelitian ini menunjukkan ada pengaruh pengetahuan keluarga dengan kemampuan keluarga dalam merawat klien gangguan jiwa di rumah. Hal ini menunjukkan bahwa ketidaktahuan atau kurangnya 
pengetahuan keluarga dalam mengenal masalah gangguan jiwa pada anggota keluarganya. Ketidaktahuan keluarga ini disebabkan karena informasi yang diperoleh tidak menyeluruh, informasi yang diperoleh tidak sesuai dengan masalah keluarga, tidak mau menghadapi situasi, tidak mau melawan tekanan dari keluarga dan selalu mempertahankan pola perilaku. Kurang informasi ini dikarenakan ketidakaktifan keluarga dalam memperoleh informasi baik dari petugas maupun dari media massa lainnya sehingga keluarga terkesan acuh dan tidak memperhatikan hal-hal yang perlu diperhatikan dalam perawatan klien gangguan jiwa dirumah. Hal ini ditunjang beberapa rumah keluarga jauh dari fasilitas kesehatan (puskesmas), akses transportasi yang sulit, juga tidak adanya listrik dibeberapa desa.

Tabel 2. Distribusi Jawaban Responden berdasarkan Variabel Penelitian terhadap Kemampuan Keluarga dalam Merawat Klien Gangguan Jiwa di Rumah di Wilayah Kerja Puskesmas Ulumanda Kabupaten Majene

\begin{tabular}{lcc}
\hline \multicolumn{1}{c}{ Variabel Penelitian } & $\mathbf{n = 3 0}$ & \% \\
\hline Kemampuan Keluarga & 9 & 30 \\
Mampu & 21 & 70 \\
Tidak mampu & 6 & 20 \\
\hline Pengetahuan & 24 & 80 \\
Baik & & \\
Kurang & 1 & 3.3 \\
\hline Tingkat Pendidikan & 29 & 96.7 \\
Tinggi & & \\
Rendah & 9 & 30 \\
\hline Peran Petugas Kesehatan & 21 & 70 \\
Berperan & & \\
Kurang Berperan &
\end{tabular}

Tabel 3. Pengaruh Pengetahuan dan Peran Petugas Kesehatan terhadap Kemampuan Keluarga dalam Merawat Klien Ganggauan Jiwa di Rumah di Wilayah Kerja Puskesmas Ulumanda Kabupaten Majene

\begin{tabular}{|c|c|c|c|c|c|c|c|}
\hline \multirow{2}{*}{ Variabel Independen } & \multicolumn{4}{|c|}{ Kemampuan Keluarga } & \multirow{2}{*}{$n=30$} & \multirow{2}{*}{$\%$} & \multirow[b]{2}{*}{$p$} \\
\hline & Mampu & $\%$ & $\begin{array}{c}\text { Tidak } \\
\text { Mampu }\end{array}$ & $\%$ & & & \\
\hline \multicolumn{8}{|l|}{ Pengetahuan Keluarga } \\
\hline Baik & 5 & 16.7 & 1 & 3.3 & 6 & 20 & 0,005 \\
\hline Kurang & 4 & 13.3 & 20 & 66.7 & 24 & 80 & \\
\hline \multicolumn{8}{|l|}{ Peran Petugas Kesehatan } \\
\hline Berperan & 6 & 20 & 3 & 10 & 9 & 30 & 0,008 \\
\hline Kurang Berperan & 3 & 10 & 18 & 60 & 13 & 70 & \\
\hline
\end{tabular}

Hal ini sejalan dengan yang dikemukakan oleh (Hawari, 2007) mengemukakan bahwa, hingga sekarang penanganan gangguan jiwa belum memuaskan, hal ini terutama terjadi di negara-negara yang sedang berkembang, disebabkan karena ketidaktahuan (ignorency) keluarga maupun masyarakat terhadap jenis gangguan jiwa. Ketidakmampuan keluarga dalam mengenal dan merawat klien gangguan jiwa dirumah karena tidak ada pengalaman sebelumnya dan keluarga menganggap sesuatu yang baru dihadapi ditunjang dengan minimnya informasi yang diperoleh, tidak seperti halnya dengan penyakit lainnya yang sering dihadapi atau dialami oleh anggota keluarga. Hal ini sejalan dengan yang dikemukakan oleh Bari (2004) didapatkan bahwa dalam keluarga kurang mampu mengenal masalah gangguan jiwa pada anggota keluarga sebanyak 64.2\%. Menurut 
Lawrance (2000) pengalaman merupakan suatu sumber pengetahuan untuk memperoleh kebenaran pengetahuan. Hal ini dilakukan dengan cara mengulang kembali pengalaman yang diperoleh baik itu pengalaman diri sendiri maupun orang lain untuk memecahkan masalah yang dihadapi.

Faktor lain yang mempengaruhi hasil perawatan klien gangguan jiwa dirumah adalah pelayanan pihak petugas kesehatan di puskesmas. Pelayanan kesehatan pada prinsipnya harus memperlakukan pasien dengan manusiawi sehingga pasien ingin kembali ke puskesmas yang bersangkutan. Hasil penelitian ini menunjukkan ada hubungan antara peran petugas kesehatan dengan kemampuan keluarga dalam merawat klien gangguan jiwa di rumah. Hal ini dikarenakan di Puskesmas Ulumanda program kesehatan jiwa merupakan program yang baru berjalan 1 tahun lebih, sehingga masih perlu pembenahan guna mengoptimalkan kerja petugas kesehatan sehingga berdampak pada penyampaian informasi dan pengetahuan petugas tentang kesehatan jiwa masih kurang, serta masih adanya beberapa desa di wilayah kerja Puskesmas Ulumanda belum teraliri oleh listrik, sehingga informasi dari media elektronik dan media massa tidak dapat diakses.

Masih kurangnya ketenagaan dan kebijakan yang diterapkan dari puskesmas sangat mempengaruhi peran petugas kesehatan jiwa di masyarakat, hal ini terlihat lokasi penelitian di Puskesmas Ulumanda, dimana penanggung jawab program kesehatan jiwa merangkap dengan program lainnya.Hal ini tidak lepas dari pengambilan kebijakan dari Kepala Puskesmas Ulumanda. Sedangkan faktor perawatan keluarga klien dengan gangguan jiwa sangatlah penting apa lagi penerimaan klien dimasyarakat masih sering dikucilkan. Dengan keterbatasan petugas sangat berdampak pada tingkat pengatahuan dan kemampuan keluarga dalam merawat klien gangguan jiwa di rumah, sehingga penyampaian informasi yang diberikan akan terbatas juga sehingga sangat berpengaruh terhadap kemampuan keluarga. Hal ini sangatlah penting guna membantu kemampuan keluarga dalam merawat klien gangguan jiwa dirumah sehingga penderita tidak menjadi beban dalam keluarga. Menurut Muchsin dkk. (2006), hubungan saling mendukung antara petugas kesehatan, keluarga dan penderita, serta keyakinan penderita terhadap pelayanan kesehatan yang signifikan merupakan faktor yang penting dalam menentukan keteraturan keluarga merawat klien, yang nantinya akan berdampak pada keberhasilan tingkat kesembuhan. Petugas kesehatan sangat berperan terhadap mutu pelayanan kesehatan dan perlu menjadi prioritas utama untuk meningkatkan sumber daya tenaga kesehatan yang berkualitas dalam rangka mewujudkan profesionalisme dalam bertugas.

\section{KESIMPULAN}

Peran petugas kesehatan merupakan faktor dominan terhadap kemampuan keluarga dalam merawat klien gangguan jiwa di rumah. Penulis menyarankan kepada keluarga agar lebih aktif mencari informasi tentang gangguan jiwa terutama untuk pengobatan dan perawatan penderita gangguan jiwa di rumah. Bagi petugas kesehatan agar meningkatkan kegiatan pencegahan gangguan jiwa dengan meningkatkan penyuluhan kepada masyarakat di wilayah kerja masing-masing.

\section{DAFTAR PUSTAKA}

Carson, W. B. (2000). Mental Health Nursing: The Nurse-Patient Journey. Philadelpia: W.B. Sounders Company.

Fredman. (2003). Family of Nursing: Teori and Pratice. Cneclicut: Appleton \& Lange.

Goldenberg, I., \& Goldenberg, H. (2004). Family Therapy an Overview. USA: Thomson.

Hawari, D. (2007). Pendekatan Holistik Pada Gangguan Jiwa Skizofrenia. Jakarta: FKUI.

Kaplan, H. I., Saddock, B. J., \& Grebb, J. A. (2010). Sinopsis Psikiatri Ilmu Pengetahuan Perilaku Psikiatri Klinis. Jakarta: Bina Rupa Aksara.

Keliat, B. A. (2003). Peran Serta Keluarga dalam Perawatan Klien Gangguan Jiwa. Jakarta: EGC.

Maramis, W. F. (2005). Catatan Ilmu Kedokteran Jiwa. Surabaya: Air Langga University Press.

Riyadi, S., \& Purwanto, I. (2010). Asuhan Keperawatan Jiwa. Yogyakarta: Graha Ilmu.

Stuart, G. W. (2009). Principles and Practice of Psychiatric Nursing. St. Louis: Mosby.

Stuart, G., \& Laraia, M. (2005). The Principle and Practise of Psychiatric Nursing. St. Louis Missouri: Elseiver Mosby. 
Suliswati, S. (2005). Konsep Dasar Keperawatan Kesehatan Jiwa. Jakarta: EGC.

Tomey, A. M., \& Alligood, M. R. (2006). Nursing Theories and Their Work. St. Louis: Mosby Year Book Inc.

Varcarolis, E. M., Carson, V. B., \& Shoemaker, N. C. (2006). Foundation Psyciatric
Mental Health Nursing: Clinical Approach. St. Louis: Sounders Elseviers. Videbeck, S. L. (2008). Buku Ajar Keperawatan Jiwa. Jakarta: EGC.

Yosep, I. (2007). Keperawatan Jiwa. Bandung: Refika Aditama. 